ISSN: 0210-7287

DOI: http://dx.doi.org/10.14201/161620199241249

\title{
LA PREMONICIÓN, LA HISTORIA Y EL SUEÑO: SOBRE LA BATALLA DE CLAVIJO
}

\section{Premonition, History and Dream: The Battle of Clavijo}

\author{
María Luisa BURGUERA NADAL \\ Universidad Jaime I, Castellón \\ burguera@uji.es
}

Recibido: junio de 2019; Aceptado: septiembre de 2019; Publicado: diciembre de 2019

Ref. Bibl. MARÍA LUISA BURGUERA NADAL. LA PREMONICIÓN, LA HISTORIA Y EL SUEÑO: SOBRE LA BATALLA DE CLAVIJO. 1616: Anuario de Literatura

Comparada, 9 (2019), 241-249

RESUMEN: Desde que el ser humano fue capaz de reflexionar, entendió que el sueño era un fenómeno fundamental en sus relaciones consigo mismo y con el mundo en torno. Basándonos en la innovadora perspectiva de Helios Jaime-Ramírez sobre el sueño, así como en su teoría sobre la ideosemántica, nos aproximaremos a la conocida leyenda de la batalla de Clavijo, incluida en De Rebus Hispaniae de Rodrigo Jiménez de Rada, redactada en el siglo XIII, también conocida como Historia de los hechos de España. En la crónica se cuenta que el rey Ramiro I tuvo un sueño que dio lugar a un suceso profundamente arraigado en la cultura popular. Nuestro propósito será analizar ese sueño desde la perspectiva de la ideosemántica, poniendo en relación la correspondencia entre la psicofisiología y el sueño. sueño.

Palabras clave: Sueño; ideosemántica; batalla de Clavijo; psicofisiología del

ABSTRACT: Since the human being was able to reflect, he understood that dreams were a fundamental phenomenon in his relationships with himself and 
with the world around him. Based on the innovative perspective of Helios JaimeRamírez on the dream, as well as on his theory about ideosemantics, we will approach the well-known legend of the battle of Clavijo, included in Rodrigo Jiménez de Rada's De Rebus Hispaniae, written in the thirteenth century, also known as History of the Facts of Spain. In the chronicle, it is said that King Ramiro I had a dream that gave rise to an event deeply rooted in popular culture. Our purpose will be to analyze that dream from the perspective of the ideosemantics, by relating the correspondence between psychophysiology and sleep. Sleep.

Keywords: Dream; Ideosemantics; Battle Of Clavijo; Psychophysiology Of

Desde que el ser humano fue capaz de reflexionar, entendió que el sueño era un fenómeno fundamental en sus relaciones consigo mismo y con el mundo entorno; las ideas sobre el tiempo y el espacio, la creación artística y las concepciones cosmogónicas e incluso las científicas, etc., todo presenta relaciones con el sueño. Basándonos en la innovadora perspectiva de Helios Jaime-Ramírez sobre el sueño, así como en su teoría sobre la ideosemántica, nos aproximaremos a la conocida leyenda de la batalla de Clavijo, incluida en De Rebus Hispaniae de Rodrigo Jiménez de Rada, redactada en el siglo XIII, también conocida como Historia de los hechos de España. En la crónica se cuenta que el rey Ramiro I tuvo un sueño que dio lugar a un suceso profundamente arraigado en la cultura popular. Nuestro propósito será analizar ese sueño desde la perspectiva de la ideosemántica, poniendo en relación la correspondencia entre la psicofisiología y el sueño.

La psicofisiología es una parte de la neurofisiología que estudia las funciones del cerebro en relación con las imágenes psíquicas. Uno de los métodos más empleados es el estudio de las imágenes cerebrales por resonancia electromagnética. En la Introducción a su libro Le Rêve dans la littérature, la musique et la science, Jaime-Ramírez (2016) va a intentar responder a la pregunta de cuáles son las correspondencias entre la psicofisiología y el sueño, de modo que, partiendo de una aproximación psicofisiológica del sueño, entiende que el sueño constituye una realidad fisiológica y psíquica que, en ciertos casos, puede ser premonitora. Parte de la ideosemántica, una teoría propia expuesta en varias publicaciones, según la cual aborda la significación de las palabras y de las estructuras lingüísticas no como conceptos abstractos, sino como una combinación funcional de imágenes psíquicas significativas que expresan la visión del mundo y del hombre. Así pues, a la ideosemántica la podemos definir como «el estudio de las imágenes de una cosmovisión representadas en estructuras lingüísticas que expresan formas de pensamiento" (Jaime Ramírez 2004, 550). El método 
ideosemántico permite no solo esclarecer la composición lexical, sino que plantea relaciones con formas de conocimiento relativas a una mentalidad, a una sociedad. Su extensión a otros campos científicos, así como al de la documentación histórica, le permite a Jaime-Ramírez establecer una funcionalidad de correlaciones entre disciplinas que, aparentemente, funcionan aisladas las unas de las otras.

En lo que se refiere a la literatura, al considerar una obra como un complejo unitario activo, la ideosemántica la estudia según el funcionamiento dinámico que se establece entre sus diversos componentes psicológicos, lingüísticos y socio históricos. "Este criterio permite ver la obra como un fenómeno de creación", afirma Jaime-Ramírez (2004, 553), «y también como una manifestación viviente del arte de un pueblo o de una civilización». En cuanto a la psicofisiología del sueño, se había supuesto que el sueño que se desarrollaba durante el acto de dormir era independiente de la actividad racional del cerebro, pero, según las investigaciones hechas por el neurofisiólogo Michel Jouvet (Université de Lyon) y el psiquiatra John Allan Hobson (Harvard Medical School), entre otros, se ha observado que, cuando se sueña, el córtex, la parte del cerebro que está en el origen de los procesos racionales, puede estar aún más activa que en el estado de vigilia. Se puede igualmente establecer la diferencia entre el sueño (acto de dormir) y el sueño como acto de soñar (el proceso onírico), según las ondas específicas emitidas por el cerebro que nos revela el electroencefalograma. Lo que se conoce como «sueño paradojal» correspondería al sueño como «historia que se sueña». Todo el proceso, que Jaime describe minuciosamente, remite a procesos del subconsciente. Y curiosamente los datos psicofisiológicos confirman la realidad de los procesos oníricos y muestran que existe una especie de conciencia en el subconsciente. En suma, el sueño revela algo de lo que se es consciente.

Jaime-Ramírez (2016, 27 y ss.) establece a continuación diferencias entre lo «real» y la «realidad» y analiza la relación entre la ficción y los procesos oníricos. Es evidente que el sueño revela una realidad y es vivido como una experiencia real. Pero, ¿̇cuál es la diferencia entre la realidad y lo real? Lo que se considera como real no nos da más que un fragmento de la realidad, el que percibimos en un cierto momento en un lugar. Lo que es real no es más que una de las formas en las que puede presentarse la realidad. La realidad puede ser percibida según dos perspectivas complementarias: como una estructura, una organización, o como una imagen funcional que se hace presente por nuestra percepción. En cuanto a la ficción y su relación con los procesos oníricos, el subconsciente no se limita a una instantánea, sino que presenta una historicidad y esta presenta relaciones con el concepto de ficción. La función de la ficción sería la puesta en marcha de la realidad. 
Igualmente, Jaime-Ramírez (2016, 35 y ss.) dedica un capítulo a la premonición, y es este aspecto el que utilizaremos para nuestra propuesta. Las formas de la experiencia corresponden a diversas maneras de ser, de modo que un acontecimiento es vivido según la idiosincrasia de la persona. Sin embargo, las experiencias que son asimiladas por el subconsciente e interpretadas por el consciente están lejos de limitarse a lo que está motivado por las circunstancias inmediatas. De la misma manera que la premonición intuitiva es previa a los acontecimientos, la decisión racional también lo es. Se podría decir que existe entre la premonición, la decisión y el hecho una relación de futuro anterior.

Vistos pues estos supuestos teóricos en los que nos basaremos para nuestro análisis, nos fijamos a continuación en el objeto de nuestro estudio. Nos aproximaremos a la conocida leyenda de la batalla de Clavijo, que se basa en un hecho que tuvo lugar en el siglo IX y en la que intervino el rey Ramiro I de Asturias contra los musulmanes y que está incluida en De Rebus Hispaniae de Rodrigo Jiménez de Rada (1989), redactada en el siglo XIII. Jiménez de Rada fue un eclesiástico, pero también militar e historiador navarro castellano, que vivió entre finales del siglo XII y la primera mitad del siglo XIII. Fue arzobispo de Toledo y fundador de la actual catedral; consejero de varios reyes navarros y castellanos, organizó la cruzada contra los almohades y dirigió la campaña de las Navas de Tolosa. También destacó en los concilios de Lyon y de Letrán. Su obra de más relevancia fue De Rebus Hispaniae, en la que se describe la historia de la Península Ibérica desde sus orígenes hasta 1243. En ella utiliza el método crítico como historiador, haciendo uso de la documentación y recurriendo a varias fuentes. Se convirtió en elemento fundamental en la redacción de la Estoria de España de Alfonso X el Sabio. De rebus Hispaniae consta de nueve libros, en los que Jiménez de Rada desarrolló una visión de conjunto de todos los territorios peninsulares. Dedica una gran parte al dominio del reino visigodo, pero también trata a los demás pueblos de la península. Y durante siglos ha sido fuente principal para el estudio de la historia de España.

Pero detengámonos en el rey Ramiro I (790-850). Sucesor de su primo Alfonso II el Casto, fue proclamado rey estando ausente de Oviedo. Esta ausencia fue aprovechada por el conde de palacio Nepociano, quien, apoyado por parte de la nobleza asturiana, intentó, sin conseguirlo, apoderarse de la corona. Derrotado Nepociano, Ramiro I se vio obligado no obstante a afrontar nuevas conspiraciones nobiliarias y desórdenes internos. El nuevo rey tenía un temperamento duro y justiciero y las crónicas le denominaron "Vara de la justicia». Durante su breve reinado también tuvo que hacer frente a los ataques de los vikingos. En el verano de 846, el emir Abd ar-Rahman II, emir de Córdoba en el siglo IX, envió contra el reino 
asturiano un ejército que penetró por los desfiladeros de la frontera riojana, impidiendo que los montañeses asturianos se estableciesen en León, hecho este a considerar para el objeto de nuestro estudio.

Veamos ahora lo que dice la crónica De Rebus Hispaniae en el capítulo 66. Establece en primer lugar una fijación cronológica, de modo que señala que lo que se cuenta sucedió durante el segundo año del reinado de Ramiro; los moros, sigue afirmando la crónica, pidieron al rey, a cambio de mantener la paz, el tributo de cien doncellas cristianas, como antes habían hecho al rey Mauregato; pero el rey Ramiro se negó y con su ejército llegó hasta tierras de Nájera, enfrentándose a su paso con los ejércitos enemigos. Los cristianos fueron derrotados en un lugar que llaman Ahuella y, posteriormente, llegaron a un collado denominado Clavijo. Allí rezaron muy devotamente. Cuando el rey se adormeció, llegó hasta él el apóstol Santiago y le dijo que a él le había concedido el Señor que guardase a toda España, que la amparase y defendiese de los enemigos de la fe y que lo iba a ayudar contra sus enemigos con la promesa de que al día siguiente los vencería con la ayuda de Dios. Le anunció que habría muchos muertos y que a estos se les concedería la gloria. Para que no dudase de su palabra, le dijo que lo vería en un caballo blanco y con una señal del mismo color. Todos deberían confesar y comulgar y entrar sin miedo en la batalla invocando el nombre de Dios y el suyo, el de Santiago. Después de haber dicho todo esto, el apóstol desapareció. Cuando el rey se levantó de su descanso, hizo llamar a todos, les contó lo sucedido en el sueño y entraron llenos de valor en la batalla. También el apóstol estuvo con ellos en el combate, actuando valientemente. Entonces dando grandes voces «iDios ayuda!» y «Santiago!», las tropas de Ramiro vencieron a los moros y allí murieron setenta mil enemigos. El rey don Ramiro se volvió entonces hacia León. Desde aquel día los cristianos, al inicio de las batallas, repiten las mismas palabras y desde entonces comenzó la Orden de Santiago. El tributo de las cien doncellas es una leyenda que alude a que en el siglo VIII el rey Mauregato accedió al trono asturiano a cambio de pagar el tributo de cien doncellas al emirato; sus sucesores pusieron fin al pago, pero Abd ar-Rahman II, en tiempos de Ramiro, se atrevió a pedir el tributo de nuevo, lo que dio origen a duros enfrentamientos entre moros y cristianos.

Hasta aquí lo relatado en el capítulo 66 de la crónica. Lo cierto es que parece ser una leyenda, si entendemos por "leyenda" un relato basado en un hecho o un personaje reales, magnificado por la fantasía o la admiración. No debe resultarnos extraño que, si bien una crónica es un subgénero literario perteneciente a la historiografía y que consiste en la recopilación de hechos históricos narrados en orden cronológico, incluya también a veces sucesos legendarios. En el sueño se alude a la batalla de Clavijo, un 
legendario enfrentamiento entendido como una de las más célebres batallas de la Reconquista, dirigida por el rey Ramiro I de Asturias. Se habría producido en el denominado "Campo de la Matanza", en las cercanías de Clavijo, en La Rioja, fechada el 23 de mayo del año 844. Sus características míticas la han hecho ser considerada en la actualidad más bien una batalla legendaria, cuya inclusión en las crónicas se debería al arzobispo Rodrigo Jiménez de Rada, y que incluiría datos de otras batallas de diferentes momentos y localizaciones, aunque es sobre todo, y a grandes rasgos, la mitificación de la segunda batalla de Albelda.

Ordoño I de Asturias, hijo de Ramiro I, se adelantó al peligro que podría suponer la nueva fortaleza de Albelda, muy cercana a Clavijo, y, en el año 859, la atacó y destruyó, causando una gran derrota a los Banu Qasi, según señala la Crónica de Alfonso III. Pero se cuenta que, después de la batalla de Clavijo, en agradecimiento, el rey Ramiro I y la reina doña Urraca instituyeron en Calahorra el "Voto de Santiago", por el que se ofrecían al Apóstol cosechas y botín de guerra por parte de los campesinos del norte de la Península. Este Voto de Santiago se renovó e institucionalizó como ofrenda nacional en 1643 para el día de su fiesta, el 25 de julio, con Felipe IV. No se conserva el diploma original expedido por el rey Ramiro I, ya que cuentan las crónicas que al parecer se extravió en el siglo XVI. Sin embargo, existen varias copias, entre otras, una procedente del Monasterio de Corias, en Asturias, que se conserva en la Biblioteca Nacional de Madrid.

Aunque la anterior batalla es una de las claves para que Santiago de Compostela se convirtiese en uno de los lugares de peregrinación por excelencia, las apariciones de Santiago en las batallas no cesarán. En 1064, en la batalla de Coímbra, combate de la Reconquista descrito en el Codex Calixtinus, manuscrito del siglo XII que contiene el más antiguo texto del Liber Sancti Iacobi, Santiago vuelve a intervenir en favor de las tropas de Fernando I de León. Las apariciones del Santo recorrerán todo el territorio peninsular mezclándose la realidad con la devoción. No obstante, no es nuestro cometido averiguar los hechos históricos sino detenernos en el análisis del relato del sueño de Ramiro I desde la perspectiva que hemos anunciado.

Partimos pues de la ideosemántica, de manera que abordamos el texto, que sería el capítulo 66 de De Rebus Hispaniae en el que se relata el sueño de Ramiro, como el estudio de las imágenes de una cosmovisión representadas en estructuras lingüísticas que expresan formas de pensamiento. Hay que añadir que nos enfrentamos a un subgénero literario, el de la crónica medieval, a caballo entre la historia y la literatura, de modo que nos encontramos frente a una serie de correlaciones de disciplinas que en este caso no funcionan aisladas. 
En cuanto a la psicofisiología del sueño, lo que se conoce como «sueño paradojal" correspondería al sueño como "historia que se sueña", es decir, lo que sueña Ramiro. Ya hemos visto antes cómo, curiosamente, los datos psicofisiológicos confirman la realidad de los procesos oníricos y muestran que existe una especie de conciencia en el subconsciente. En suma, el sueño revela algo de lo que se es consciente. Así pues, el sujeto que sueña, Ramiro, es plenamente consciente de la historia que sueña. En cuanto al dinamismo onírico, el neurofisiólogo Pierre Magnin no duda en hablar de "tempestad del cerebro". "Desde el siglo XIX el sueño está asociado a las imágenes mentales, a las formas premonitorias, a la imaginación", argumenta Jaime-Ramírez (2016, 25), «que son las fuentes de la concepción literaria y también musical». Hay que añadir que, dice Jaime, por su importancia vital y significativa, un sueño es vivido normalmente como un fenómeno positivo. Y así es en nuestro caso, puesto que el sueño anuncia la presencia del santo protector y la victoria en la batalla.

Ya hemos mencionado que es evidente que el sueño revela una realidad y es vivido como una experiencia real. La realidad puede ser percibida según dos perspectivas complementarias: como una estructura, una organización o como una imagen funcional que se hace presente por nuestra percepción y ese sería el caso del sueño de Ramiro. Veamos cómo es la percepción en el sueño. Cuando soñamos, estamos aislados de la realidad exterior; estamos con nosotros mismos. La percepción de todo ese mundo y de esas imágenes puede ser debida a la puesta en acción del subconsciente que actúa sobre la conciencia reflexiva. Por otra parte, «la percepción onírica participa de las mismas características psicofisiológicas que las que se experimentan en el estado de vigilia" (Jaime-Ramírez 2016, 129; mi traducción). Sin embargo, a diferencia de la percepción en el estado de vigilia, que centra su atención sobre objetos precisos, la percepción onírica engloba, de una manera casi instantánea, una diversidad creciente de situaciones. Así, los acontecimientos vividos durante el sueño no se suceden según una sucesión lógica, sino que se presentan contiguos unos con los otros. Eso podría explicar por qué el lenguaje de los sueños no se estructura de la misma manera que el lenguaje empleado en el estado de vigilia.

¿Cómo es el lenguaje onírico? Todo lenguaje, incluido el lenguaje onírico, está organizado según una estructura que revela un sentido. Cuando se sueña no solo entendemos lo que los personajes nos dicen, sino que podemos interpretar las situaciones oníricas. En el lenguaje onírico las personas nos hablan, pero desde el punto de vista acústico, no hay sonidos. Por otro lado, las imágenes oníricas aparecen y desaparecen sin presentar una continuidad entre ellas (Jaime-Ramírez 2016, 130 y ss.). El lenguaje onírico no está organizado como lo está el del estado de vigilia; está compuesto 
por imágenes significativas: la concordancia del sistema lingüístico con las funciones semánticas de las imágenes es lo que constituye la estructura del lenguaje onírico. Por su función representativa las significaciones de esas imágenes podrían constituir un lenguaje simbólico.

Las imágenes psíquicas del sueño se desarrollan siguiendo los acontecimientos que, incluso sin tener relación con la realidad circundante, están constituidos por la puesta en acción de todo lo que hemos vivido de una manera consciente, es decir, que están en relación con nuestra memoria. Pero pueden ser también la consecuencia onírica de nuestros deseos, de nuestras aspiraciones, es decir, que ellos representan lo que hubiéramos querido vivir. Y ese sin duda es el caso del sueño que nos ocupa: el deseo que posee Ramiro de la victoria sobre sus adversarios. Por otra parte, las situaciones que vivimos durante el sueño se desarrollan como una especie de puesta en escena en la que participamos como protagonistas, pero también como espectadores. Y así es, pues Ramiro aparece como protagonista y como espectador del sueño. En este aspecto, la trama de las escenas oníricas corresponde a la estructura de la ficción (Jaime-Ramírez 2016, 163).

Algo que incide muy directamente con nuestro objeto de estudio es el hecho de que, al ser escrita después de los acontecimientos que analiza, la historiografía establece una fenomenología presente del pasado. Aclara Jaime-Ramírez que utiliza el término fenomenología en el sentido de que todo acontecimiento existe si es considerado como real por nuestra conciencia. El relato histórico es percibido por el lector como la representación real de acontecimientos del pasado. Así, la historia es, en relación con el pasado, un futuro. De ese modo la simultaneidad del pasado y del futuro tiene lugar pues en el presente.

Una de las significaciones que forman parte del complejo ideosemántico del sueño es la de la visión. Por ello, en la literatura medieval la palabra "visión" puede reemplazar a la palabra sueño (Jaime Ramírez 2016, 18; mi traducción), pero esta aparición, más que como un fenómeno onírico personal, se percibe como un mensaje normalmente enviado por un poder divino; ese sueño se produce como una visión y también como una advertencia. Lo encontramos muchas veces en la obra de Virgilio, en otros muchos ejemplos y también en nuestro caso, ya que el sueño de Ramiro es un sueño de premonición. Y ese sueño se produce como una visión y también como una advertencia.

Hemos analizado pues un fragmento de una crónica medieval que incluye un sueño de premonición abordándolo desde una perspectiva innovadora y, a la vez, rigurosa, ya que nos hemos basado en la ideosemántica y en el acercamiento al sueño desde un punto de vista psicofisiológico. Así pues, un hecho legendario del siglo IX, en el que se mezclan la ficción y la 
realidad, es recogido en una crónica del siglo XIII y es la base de historias posteriores. Ese hecho legendario incluye un sueño de premonición pues avisa de algo que sucedió posteriormente. Desde una perspectiva ideosemántica, nos atreveríamos a proponer que la finalidad del relato sería el afianzamiento de la Reconquista, fundamental para entender la cosmovisión peninsular del siglo XIII. Un dato que cumple considerar sería la etimología de la palabra "Clavijo", ya que esta procede del latín Claviculum, originariamente 'hinchazón', pero posteriormente, y según Emilio Alarcos Llorach (en Ortiz Trifol 1982, 85-86), 'elevación'.

En suma, el hecho de que el objeto de nuestro estudio, el capítulo 66 de De rebus Hispaniae, no sea una obra exclusivamente literaria no nos impide verla como un fenómeno de creación, fruto de la imaginación como proceso psíquico que pone en acción las imágenes mentales, y también como una manifestación profundamente arraigada en la cultura popular del arte de un pueblo, de una tradición e incluso de una civilización.

\section{REFERENCIAS}

Burguera, M. ${ }^{a}$ Luisa, ed. 2004. Textos clásicos de teoría de la literatura. Madrid: Cátedra.

JaIme-RAmírez, Helios. 2004. «Ideosemántica de la novelística argentina». En Textos clásicos de teoría de la literatura, editado por M. ${ }^{a}$ Luisa Burguera, 548-553. Madrid: Cátedra.

Jaime-Ramírez, Helios. 2016. Le Rêve dans la littérature, la musique et la science. París: Fauves.

JimÉnEZ DE RADA, Rodrigo. 1989. Historia de los hechos de España. Editado y traducido por Juan Fernández Valverde. Madrid: Alianza.

Ortiz Trifol, Carmen. 1982. Toponimia riojana. Logroño: Diputación de La Rioja. 
